Research report

\title{
Illness representations of depression and perceptions of the helpfulness of social support: Comparing depressed and never-depressed persons
}

\author{
Manja Vollmann ${ }^{a, *}$, Margreet Scharloo $^{b}$, Christel Salewski $^{c}$, Alexander Dienst ${ }^{a}$, \\ Klaus Schonauer ${ }^{a}$, Britta Renner ${ }^{a}$ \\ a University of Konstanz, Germany \\ b Leiden University Medical Center. The Netherlands \\ c University of Applied Sciences Magdeburg-Stendal, Germany
}

\section{A R T ICLE I N F O}

Keywords:

Depression

Illness representations

Social support

Lay theories

\begin{abstract}
A B S T R A C T
Background: Interactions between depressed persons and persons within their social network are often characterized by misunderstanding and unsuccessful social support attempts. These interpersonal problems could be fostered by discrepancies between depressed and neverdepressed persons' illness representations of depression and/or discrepancies in the perceived helpfulness of supportive behaviors.

Methods: Illness representations of depression (IPQ-R) and perceptions of the helpfulness of different social support behaviors (ISU-DYA and ISAD) were assessed in 41 currently depressed persons and 58 persons without a history of depression.

Results: Never-depressed persons perceived depression as more controllable by treatment and as less emotionally impairing than depressed persons, but also as having more severe consequences. Neverdepressed persons considered activation-oriented support (motivation to approach problems) as more helpful and protection-oriented support (allowance to draw back) as less helpful in comparison to depressed persons.

Limitation: Data were collected in unrelated samples of depressed and never-depressed persons. Conclusions: Discrepancies in illness representations and perceptions of the helpfulness of social support do exist and may be the origin of problematic social interactions between depressed patients and persons within their social network. Therapeutic interventions should address the issue of conflicting perceptions and encourage depressed patients to acknowledge and discuss this topic within their social network
\end{abstract}

\section{Introduction}

Social support has been identified as an important factor in the course and outcome of depressive disorders. Studies have indicated that low levels of social support increase the risk of developing a major depression over the lifespan (Slavich et al., 2009; Stice et al., 2004; Wade and Kendler; 2000). Moreover, impaired social support has been found to be associated with a

\footnotetext{
* Corresponding author. University of Konstanz. Department of Psychological Assessment and Health Psychology, P.O. Box 47, D-78457 Konstanz. Germany. Tel.: + 497531882354 ,

E-mail address: manja.vollmann@uni-konstanzde (M. Vollmann).
}

greater severity of depressive symptoms, a delayed recovery from a major depression episode and the successive recurrence of depression (Burcusa and lacono, 2007; Gladstone et al., 2007; Zuroff and Blatt, 2002). Thus, receiving social support seems to buffer against the onset of depression and to facilitate recovery from a depressive episode.

However, many studies found that social interactions between depressed persons and their social network are characterized rather by rejection and lack of understanding than by empathy and helpful social support processes. When asking depressed persons about their social support, they frequently report feelings of being misunderstood and a high number of conflicts in their social relationships (Alexander, 
2001; Keitner et al., 1995; Sheeber et al., 2007). Moreover, depressed persons perceive themselves to be short of supportive social ties and actually hold this lack of support responsible for hindering their recovery from depression (Gladstone et al., 2007; Lynch et al., 1999; Strine et al., 2009). Research focusing on the perspective of the depressed persons" social network strongly corroborates the depressed persons' perceptions of disturbed social interactions. A number of studies examining the impact of depression on the social environment show that depressed persons evoke negative emotions, unfavorable evaluations and social rejection in others, particularly in longterm relationships (for a meta-analytic overview, see Marcus and Nardone, 1992 and Segrin and Dillard, 1992; Angermeyer and Matschinger, 2004; Coyne et al., 2002; de Toledo Piza Peluso and Blay, 2009; Hale et al., 1997).

These results on interpersonal problems suggest a considerable mismatch between the need for social support in depressed persons and the actual quantity and quality of support provided by the social network. Within a comprehensive framework of self-regulation, seeking and providing social support can be conceptualized as a way of coping with health threats and illnesses. According to the self-regulation model (SRM; Leventhal et al., 1998; Petrie and Weinman, 2006), illness-related coping responses are strongly determined by the person's subjective representations of the illness. Illness representations are derived from a variety of sources including own experience of the illness, experiences of the illness in close others, views on the illness presented in the media as well as socially shared beliefs about the illness rooted in culture and history (Baumann, 2003; Petrie and Weinman, 2006; Weinman et al., 2003). Thus, patients as well as individuals who have not been personally affected by an illness develop illness representations that have an impact on their behavior. Applying the SRM to depression, it has been found that depressed persons' beliefs about their illness influence their coping responses such as seeking medical treatment and social support (Edwards et al., 2007; Kelly et al., 2007). Furthermore, the model implies that healthy persons' illness representations of depression influence their supportive behaviors towards depressed persons and their ideas about what constitutes helpful support.

As illness representations of depressed and healthy persons are based on different sources of information (e.g., the information gathered through "looking-at depression" by healthy persons or/and "living-with depression" by depressed persons), one plausible explanation for the interpersonal problems between depressed persons and their social network would be that their representations of the illness and their perceptions of the helpfulness of social support are discrepant. Previous studies comparing illness representations of depressed and non-depressed persons lend support to this explanation showing significant differences in symptom perceptions, perceptions of the impact of the disease, perceived illness duration, controllability of the condition and causal attributions (Coyne et al., 1998; Fortune et al., 2004; Kirk et al., 2000).

Discrepancies in illness representations between patients with chronic illnesses and members of their social network have been found to be associated with poorer psychological adjustment, lower relationship quality and impaired social support processes (Figueiras and Weinman, 2003; Heijmans et al., 1999; Quiles Marcos et al., 2009). Research showed that both spousal overestimation and spousal underestimation of the seriousness of the patient's illness as compared to the patient's perceptions is related to lower levels of received social support and lower satisfaction with social support reported by the patients (Benyamini et al., 2007; Heijmans et al., 1999; Martire et al., 2006).

In accordance with the assumptions of the SRM, there is empirical evidence that care givers' representations of the patient's illness have a strong influence on their supportive behaviors towards the patient (cf., Weinman et al., 2003). First, it has been demonstrated that spouses who perceived the patient's illness as comprising only few symptoms and as causing nonsevere consequences provided the patient with less social support (Benyamini et al., 2007). Second, spouses who overestimated the seriousness of the patient's illness experienced greater stress and less mastery in providing social support than spouses whose illness representations were concordant with those of the patients (Martire et al., 2006). Third, it has been suggested that support providers' beliefs about an illness have an impact on their perceptions of how much support the patient might need and on their perceptions of what kind of support might be most helpful (Lehman et al., 1986).

These findings suggest that patients and healthy persons may differ in their illness representations as well as in their perceptions of the helpfulness of social support. Also, illness representations seem to influence the perceptions of the helpfulness of social support both within patients and healthy persons. Previous studies investigating discrepancies in illness representations between depressed and non-depressed persons predominantly focused on the severity and the causes of depression while neglecting other illness representation dimensions such as timeline or cure/control (Cornwall et al., 2005; Coyne et al., 1998; Kirk et al., 1999, 2000; Kuyken et al., 1992). With regard to social support in case of depression, previous studies have focused exclusively on perceptions of the quantity of social support, while not a single study has investigated depressed and non-depressed persons' perceptions of the helpfulness of different supportive behaviors. Moreover, only little is known about the relationship between illness representations of depression and the perceived helpfulness of supportive behaviors.

Therefore, in the present study, illness representations of depression and perceptions of appropriate social support when facing depression were examined among currently depressed persons and persons with no history of depression. Three research goals were addressed. The first goal was to contrast representations of depression among depressed and neverdepressed persons with regard to the representational attributes suggested by the SRM (Leventhal et al., 1998). The second goal was to compare depressed and never-depressed persons' perceptions of the helpfulness of different social support behaviors. Finally, the third goal was to examine the impact of illness representations on perceptions of the helpfulness of social support among depressed and never-depressed persons.

\section{Methods}

\subsection{Sample}

Participants were approached individually and were invited to participate in a research project about views on depression. Once they agreed to take part in the study, they 
received a booklet containing the questionnaires and were asked to return the completed booklet by mail using prestamped addressed envelopes.

The subsample of depressed persons was recruited from the Reichenau Psychiatry Center in Konstanz, Germany and a depression self-help group in Stuttgart, Germany. A total of 53 persons returned completed questionnaires (response rate: $41 \%$ ). However, 12 persons missed the inclusion criteria of being currently depressed as indicated by the Patient Health Questionnaire 9-Item Depression Module (PHQ-9, Spitzer et al., 1999) and were therefore excluded from the study. The final sample consisted of 41 depressed persons ( 23 women/18 men) with a mean age of 49.56 years ( $S D=10.40$, range: $17-67$ years).

The never-depressed persons subsample was recruited among visitors of a public library in Konstanz, Germany. Altogether, 81 persons returned completed questionnaires (response rate: $54 \%$ ). Of these, 23 persons were not included in the study because they either were currently depressed as indicated by the PHQ-9 $(n=4)$ or reported a history of depression $(n=19)$. The final sample consisted of 58 neverdepressed persons ( 35 women/ 23 men) with a mean age of 42.69 years $(S D=12.92$, range: $18-77$ years $)$.

\subsection{Measures}

\subsubsection{Current depression status}

To diagnose the current depression status, the German version of the Patient Health Questionnaire 9-Item Depression Module (PHQ-9; Gräfe et al., 2004; Spitzer et al., 1999) was used. The PHQ-9 consists of nine items each referring to one of the nine DSM-IV criteria for major depression. Participants were asked to indicate the frequency with which each symptom was experienced over the past two weeks on a 4-point scale ranging from 0 'not at all' to 3 'nearly every day', with a highest possible score of 27. Cronbach's alpha was .94. In line with previous studies, a cutoff score of 10 was used to define the depression status (Kroenke et al., 2001; Patten and Schopflocher, 2009).

\subsubsection{Illness representations}

A modified German version of the Illness Perceptions Questionnaire-Revised (IPQ-R; Moss-Morris et al., 2002; Salewski and Bleher, 2010) was used to assess the depressed and never-depressed persons' cognitive and emotional representations of depression. Following the recommendation of Moss-Morris et al. (2002) to adapt the IPQ-R to specific illnesses, for the present study, the word 'illness' was replaced with the word 'depression' throughout the questionnaire.

The first part of the IPQ-R measures the identity dimension with a list of 24 symptoms based on the DSM-VI criteria for major depression disorder (cf., Fortune et al., 2004). This dimension refers to symptoms perceived as being part of depression. Depressed persons were asked to rate whether they have experienced each symptom since their illness (yes/no), and if yes, whether they believe the symptom to be specifically related to their depression (yes/no). Never-depressed persons were asked to indicate to what extent they regard each symptom as typical of depression on a 4-point scale from 1 'not at all typical' to 4 'very typical'.

The second part of the IPQ-R contains subscales assessing timeline (acute/chronic timeline, 6 items / cyclical timeline, 4 items), consequences ( 6 items), cure control (personal control,
6 items / treatment control, 5 items), coherence ( 5 items) and emotional representations ( 6 items). Responses were given on a 5-point scale from 1 'strongly disagree' to 5 'strongly agree'. Higher scores on these scales reflect stronger beliefs in a long duration and more variability in the symptoms of depression, a greater perceived impact of depression on life, stronger beliefs in the effectiveness of controlling depression by own behavior and by medical treatment, a higher extent of understanding depression and stronger emotional responses to depression. Two different versions of these scales were devised in order to assess depressed persons' representations of their own depression and to assess never-depressed persons' representations of depression in general. The reliabilities of the subscales were sufficient to adequate (Cronbach's alphas: $.50-.85$ ) except for the timeline cyclical scale (Cronbach's alpha: .23). This scale was therefore excluded from further analyses.

The third part of the IPQ-R measures causal attributions for developing a depression by differentiating between psychological attributions such as stress and family problems ( 6 items), risk factor attributions such as heredity and health-related risk behaviors ( 8 items), immune attributions such as pollution and viruses ( 3 items), accident attribution ( 1 item) and chance attribution (1 item). On a 5-point scale from 1 'strongly disagree' to 5 'strongly agree', depressed persons answered the items with regard to their own depression, whereas never-depressed persons referred to causes for depression in general. The internal consistencies of the causal attribution scales were satisfactory (Cronbach's alphas: .76-.78).

\subsubsection{Perceived helpfulness of social support}

A modified version of the Inventory of Social Support in Dyads (ISU-DYA; Winkeler and Klauer, 2003) was used to assess the perceived helpfulness of three different forms of social support. The three support-subscales of the ISU-DYA measure emotional support (i.e., assurance and sympathy, 15 items), instrumental support (i.e., tangible assistance, 7 items) and informational support (i.e., information and guidance, 12 items). For the present study, the items were adapted to measure the helpfulness of social support provided by a friend when facing depression. Two different versions of the ISU-DYA were devised for depressed and never-depressed persons. Patients rated how helpful the different support behaviors would be for themselves, whereas never-depressed persons rated how helpful the support behaviors would be for a depressed friend. Responses were given on a 4-point scale from 1 'not at all helpful' to 4 'very helpful'. All scales had a good reliability (Cronbach's alphas: .71-.83).

The newly developed Inventory for Protection and Activation in Depression (ISAD; cf. Dienst, 2009) was used to assess the helpfulness of two oppositional directions of supportive behaviors that can be seen as promising in improving the emotional state of a depressed person. The ISAD distinguishes between activation-oriented support (motivating to approach problems, distracting from sad mood; e.g., Hautzinger, 2003) and protection-oriented support (allowing to draw back, encouraging to let out sadness; e.g., Kraus and Koch, 2006), and consists of two scales with 7 items each. Similar to the Inventory of Social Support in Dyads, the ISAD focused on friend support, was answered on a 4-point scale and was provided in two different versions for depressed and never-depressed 
persons. The two-factor structure could be confirmed and the reliabilities were satisfactory (Cronbach's alphas: .84 and .73).

\subsection{Statistical analyses}

To contrast depressed and never-depressed persons' beliefs on which symptoms are related to depression, the rank orders of the symptoms identified for the two groups were compared by performing a profile correlation analysis of the depressed persons' and the never-depressed persons' symptom profiles. Depressed and never-depressed persons' illness representations of depression and perceptions of the helpfulness of social support were compared by using multivariate analyses of variance (MANOVA). The relationship between illness representations and perceptions of the helpfulness of social support among depressed and neverdepressed persons was analyzed by means of correlation analyses.

\section{Results}

3.1. Comparing depressed and never-depressed persons on illness representations of depression

Table 1 shows for each item of the identity subscale of the IPQ-R the percentage of depressed persons who perceive the symptom as being part of their depression as well as the neverdepressed persons' mean rating of the typicality of the symptom for depression. The profile correlation analysis including these two symptom profiles yielded a highly significant result, $r=.91, p<.001$. This indicates a high consensus between the two groups regarding the symptoms perceived as being part of depression.

The MANOVA with the IPQ-R subscales timeline, consequences, personal control, treatment control, coherence and emotional representations as dependent variables revealed a significant overall effect, $F(6,89)=11.80, p<.001 ; \eta^{2}=.44$. Subsequent analyses yielded significant group differences on consequences, treatment control and emotional representations (see Table 2). Depressed persons perceived depression as less controllable by treatment and as inducing stronger emotional reactions compared to never-depressed persons. Interestingly, never-depressed persons perceived more severe consequences caused by depression than depressed persons.

The MANOVA with the five causal attributions subscales as dependent variables yielded a significant overall effect, $F(5$, $85)=9.07, p<.001 ; \eta^{2}=.35$. Subsequent analyses revealed that never-depressed persons had significantly stronger beliefs about four of the five types of causes compared to depressed persons (see Table 3 ). Never-depressed persons were more convinced that depression is caused by risk factors such as heredity and health-related risk behaviors, specifically alcohol and drug consumption. They also endorsed immunity impairments as cause of depression to a greater extent than depressed persons. Finally, they saw depression as more likely to be caused by accidents or chance. However, depressed and neverdepressed persons agreed on psychological causes such as stress and family problems, and perceived these as the main cause of depression.
Table 1

Depressed and never-depressed persons' profiles of symptoms that are perceived as related to depression.

\begin{tabular}{|c|c|c|}
\hline 4 & $\begin{array}{l}\text { Depressed persons: } \\
(\%)\end{array}$ & $\begin{array}{l}\text { Never depressed persons } \\
M(S D)\end{array}$ \\
\hline Loss of joy & 927 & $374(44)$ \\
\hline $\begin{array}{l}\text { Feelings of } \\
\text { hopelessness }\end{array}$ & 927 & $3.71(46)$ \\
\hline Depressed mood & 902 & $3.71(46)$ \\
\hline $\begin{array}{l}\text { Thoughts about } \\
\text { death }\end{array}$ & 902 & $3.55(63)$ \\
\hline $\begin{array}{l}\text { Tiredness or loss of } \\
\text { energy }\end{array}$ & 902 & $353(50)$ \\
\hline Sleep problems & 902 & $3.47(57)$ \\
\hline $\begin{array}{l}\text { Concentration } \\
\text { problems }\end{array}$ & 902 & $347(57)$ \\
\hline Loss of interest & 878 & $3.78(46)$ \\
\hline $\begin{array}{l}\text { Feelings of } \\
\text { worthlessness }\end{array}$ & 878 & $3.76(.43)$ \\
\hline $\begin{array}{l}\text { Restlessness, feeling } \\
\text { of hurry }\end{array}$ & 829 & $3.05(87)$ \\
\hline Sulicidal ideation & 756 & $3.52(60)$ \\
\hline Slowdown & 732 & $3,39(56)$ \\
\hline Feelings of guilt & 707 & $3.47(60)$ \\
\hline $\begin{array}{l}\text { Loss of interest in } \\
\text { sex }\end{array}$ & 70.7 & $311(70)$ \\
\hline $\begin{array}{l}\text { Problems with } \\
\text { decision making }\end{array}$ & 683 & $3.47(60)$ \\
\hline Increased iritability & 610 & $304(68)$ \\
\hline $\begin{array}{l}\text { Feeling of having } \\
\text { heavy limbs }\end{array}$ & 610 & $275(77)$ \\
\hline Decrease in appetite & 58.5 & $2.98(52)$ \\
\hline $\begin{array}{l}\text { Painful muscles, } \\
\text { limbs or joints }\end{array}$ & 48.8 & $2,33(64)$ \\
\hline Weight gain & 439 & $2.62(67)$ \\
\hline Weight loss & 41.5 & $2.60(65)$ \\
\hline Increase in appetite & 415 & $236(72)$ \\
\hline Backache & 41.5 & $233(64)$ \\
\hline Headaches & 341 & $274(66)$ \\
\hline
\end{tabular}

a $\%$ of depressed persons who have experienced the symptom and perceive it as part of their depression.

b Non-depressed persons' mean typicality rating of a symptom on a scale from 1 'not at all typical' to 4 'very typical'.

Table 2

Comparing depressed and never-depressed persons on illness representations of depression.

\begin{tabular}{|c|c|c|c|}
\hline & $\begin{array}{l}\text { Depressed persons } \\
M(s D)\end{array}$ & $\begin{array}{l}\text { Never-depressed } \\
\text { persons } \\
M(S B)\end{array}$ & Fvalue \\
\hline $\begin{array}{l}\text { Timeline } \\
\text { chronic }\end{array}$ & $3.76(51)$ & $3.65(54)$ & 0.89 \\
\hline Consequences & $4.04(.50)$ & $439(39)$ & $15,12^{* *}$ \\
\hline $\begin{array}{l}\text { Personal } \\
\text { control }\end{array}$ & $3.36(77)$ & $3.57(88)$ & 1.42 \\
\hline $\begin{array}{l}\text { Treatment } \\
\text { control }\end{array}$ & $3.41(51)$ & $4.01(46)$ & $3677^{* * *}$ \\
\hline $\begin{array}{l}\text { Whess } \\
\text { coherence }\end{array}$ & & $296(.75)$ & 031 \\
\hline $\begin{array}{l}\text { Emotional } \\
\text { representations }\end{array}$ & $4.08(59)$ & $3.80(47)$ & $6.60 \%$ \\
\hline
\end{tabular}

${ }^{*} p<.05,{ }^{* * *} p<.001$ 
Table 3

Comparing depressed and never-depressed persons on causal attributions for developing a depression.

\begin{tabular}{|c|c|c|c|}
\hline & $\begin{array}{l}\text { Depressed persons } \\
M(S D)\end{array}$ & $\begin{array}{l}\text { Never depressed } \\
\text { persons } \\
M(S D)\end{array}$ & Fralue \\
\hline $\begin{array}{l}\text { Psychological } \\
\text { attributions }\end{array}$ & $4.08(64)$ & $4.16(48)$ & 0.42 \\
\hline Risk factor & $2.66(74)$ & $3,31(56)$ & $22.20^{* *}$ \\
\hline $\begin{array}{l}\text { Immunity } \\
\text { attributions }\end{array}$ & $2.04(93)$ & $2.62(.90)$ & $912^{*}$ \\
\hline $\begin{array}{l}\text { Accident } \\
\text { attribution }\end{array}$ & $2.16(1.42)$ & $374(1,10)$ & $3544^{\circ *}$ \\
\hline $\begin{array}{l}\text { Grance } \\
\text { attribution }\end{array}$ & $214(1.23)$ & $2.83(102)$ & $8.67^{*}$ \\
\hline
\end{tabular}

${ }^{* *} p<.01,{ }^{* * *} p<.001$

3.2. Comparing depressed and never-depressed persons on perceptions of the helpfulness of social support in the face of depression

With regard to the helpfulness of social support, the MANOVA with the three forms of supportive behaviors (emotional, instrumental and informational) and the two directions of supportive behaviors (activation-oriented and protection-oriented) as dependent variables yielded a significant overall effect, $F(5,91)=3.57, p<.01 ; \eta^{2}=.16$. Further analyses showed that depressed and never-depressed persons did not differ in their perceptions of the helpfulness of emotional, instrumental and informational support (see Table 4). However, significant group differences in the perceptions of the helpfulness of activation-oriented and protection-oriented support did emerge. Activation-oriented support was regarded as being more helpful by neverdepressed persons, while protection-oriented support was perceived as being more helpful by depressed persons.

3.3. Relationship between illness representations and perceptions of the helpfulness of social support among depressed and neverdepressed persons

Correlations between illness representations and perceptions of the helpfulness of social support among depressed and never-depressed persons are presented in Table 5. Depressed persons regarded activation-oriented support behaviors as more helpful when they perceived depression

Table 4

Comparing depressed and never-depressed persons on perceptions of the helpfulness of supportive behaviors.

\begin{tabular}{|c|c|c|c|}
\hline & $\begin{array}{l}\text { Depressed persons } \\
M(S D)\end{array}$ & $\begin{array}{l}\text { Never-depressed } \\
\text { persons } \\
M(S D)\end{array}$ & Fvalue \\
\hline Emotional support & $3.27(.39)$ & $324(32)$ & 0.19 \\
\hline Instrumental support & $316(.40)$ & $303(40)$ & 290 \\
\hline Infot national stupport & $234(54)$ & $2.43(40)$ & 1.02 \\
\hline $\begin{array}{l}\text { Activation oriented } \\
\text { support }\end{array}$ & $254(63)$ & $2.84(39)$ & $8.34^{*}$ \\
\hline $\begin{array}{l}\text { Protection oriented } \\
\text { support }\end{array}$ & $2.83(50)$ & $255(39)$ & $944^{*}$ \\
\hline
\end{tabular}

as being non-chronic, as controllable by treatment and as caused by immunity malfunctioning. Among never-depressed persons, psychological attributions were positively associated with the perception of emotional support and instrumental support as helpful. Instrumental support was additionally perceived as more helpful when risk factors were considered as cause for depression. The perceived helpfulness of informational support was positively related to the perception of depression as having less severe consequences and as being highly controllable by own behavior. Furthermore, activation-oriented support was regarded as more helpful when depression was perceived as controllable by own behavior and when the development of a depression was attributed to psychological factors and to failing immunity. The perceived helpfulness of protection-oriented support was positively associated with having a more coherent picture of depression.

\section{Discussion}

This study is the first to assess depressed and neverdepressed persons' perceptions of the helpfulness of different supportive behaviors and quantify the associations between illness representations and perceptions of social support within the two groups.

The comparison between depressed and never-depressed persons" illness representations of depression yielded a complex result pattern. Depressed and never-depressed persons have similar views regarding symptoms related to depression, the chronic timeline of depression, the degree of personal control over depression, illness coherence and psychological attributions as cause for depression, indicating that some dimensions of illness representations of depression are socially shared. However, never-depressed persons seem to underestimate the emotional impact of the illness and perceive depression as more severe, but also as more amenable to treatment. These results are in line with previous finings that healthy people recognize the serious nature of depression for others (Barry et al., 2000), but at the same time underestimate the emotional impact of the illness (Kirk et al., 2000 ), mostly seeing positive prospects of recovery from depression (Prins et al., 2008). Our findings partly support the assumption that never-depressed persons tend to minimize the seriousness of depression (Coyne et al., 1998; Fortune et al., 2004; Kirk et al., 2000). Further, it was found that neverdepressed persons had stronger beliefs that depression is also caused by controllable factors such as alcohol and drug consumption as well as external factors such as pollution, viruses and accidents than depressed persons. Earlier research shows that most people in depressed and nondepressed samples give a multi-dimensional explanation for depression, which is in line with our results (Prins et al., 2008). The existing discrepancies in illness representations could be a vital source for problematic communications and conflicts in social interactions between depressed and neverdepressed persons. Previous research in other illnesses has shown that divergent illness perceptions in patient-relative dyads relate to poor outcomes (Heijmans et al., 1999; Quiles Marcos et al., 2009). Moreover, research on social support provision to patients with chronic illnesses suggests that especially the expression of problem minimization has 
Table 5

Correlations between illness representations and perceptions of the helpfulness of social support among depressed and never-depressed persons.

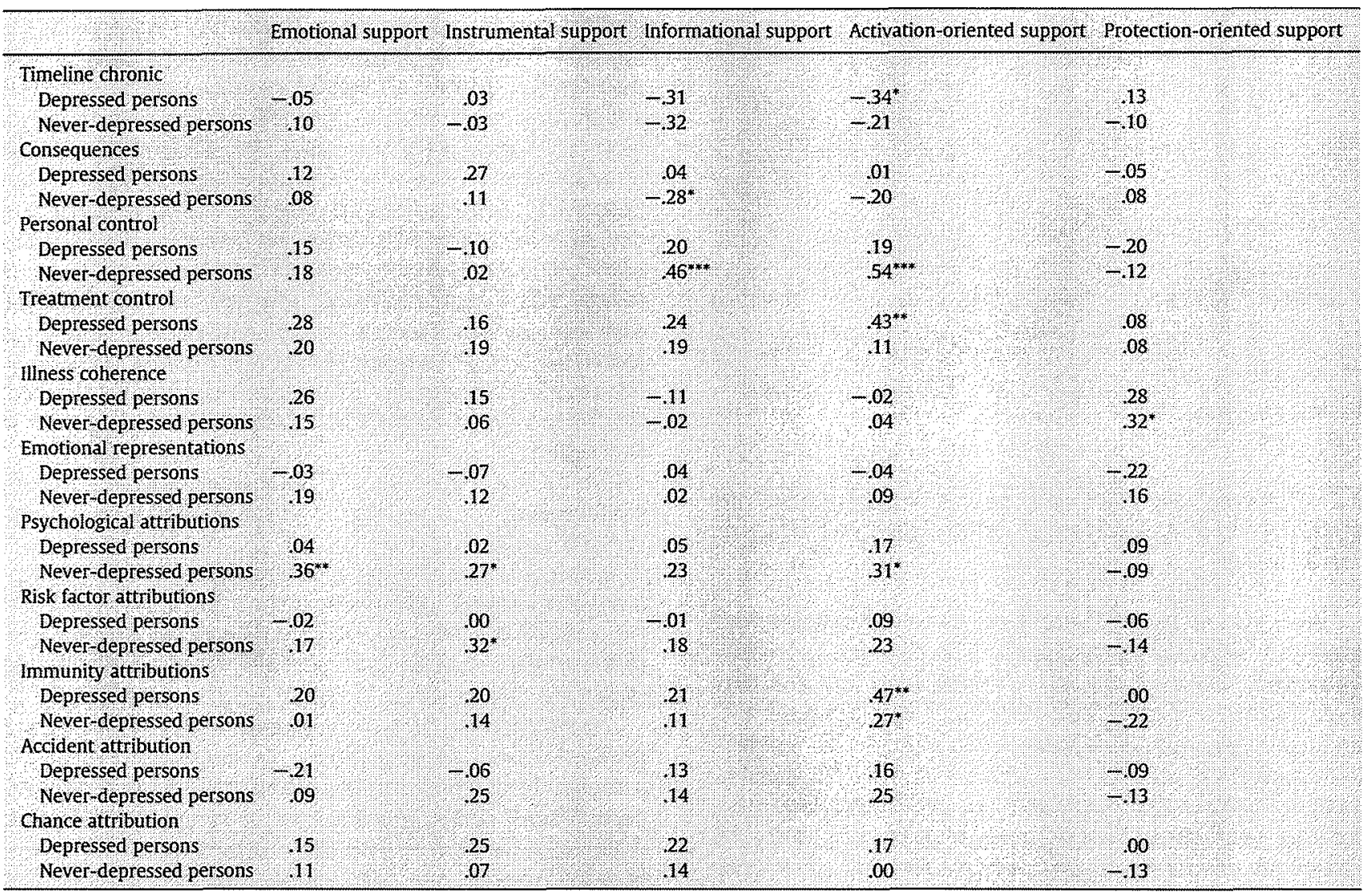

${ }^{*} p<.05,{ }^{* *} p<.01,{ }^{* * *} p<.001$.

negative effects on the patients' well-being and social functioning (cf., Weinman et al., 2003). Minimizing the seriousness of the illness is perceived by the patient as rather unhelpful, presumably because it gives the patient the impression of not being taken seriously (Heijmans et al., 1999; Lehman et al., 1986; Wortman and Lehman, 1985).

Comparing depressed and never-depressed persons' perceptions of the helpfulness of social support, different result patterns emerged for the different forms and directions of supportive behaviors. With regard to the different forms of supportive behaviors, a high consensus between depressed and never-depressed persons was found. The extent to which emotional, informational and instrumental support behaviors from friends were perceived as helpful was equal between depressed and never-depressed persons. Both groups perceived emotional support as most helpful and informational support as least helpful, which is in line with findings of studies in patients with other illnesses (e.g., cancer; Helgeson and Cohen, 1996; Dakof and Taylor, 1990). With regard to the different directions of social support behaviors, however, substantial discrepancies in the perceived helpfulness occurred. Depressed persons perceived protection-oriented support behaviors as being more and activation-oriented support behaviors as being less helpful compared to neverdepressed persons. These findings imply that depressed persons would rather like their friends to allow them to draw back and to express their sad mood, whereas neverdepressed persons are more inclined to motivate a depressed friend to become active and to approach his/her problems. The never-depressed persons' perception of the helpfulness of activation-oriented support is congruent with research showing the effectiveness of behavioral activation in the treatment of depression (Cuijpers et al., 2007; Houghton et al., 2008). However, given the discrepancy between the perceptions of depressed and never-depressed persons, social support attempts will most likely end in failure as the supportive actions do not meet the current needs of the depressed persons. In the long run, these unsuccessful support attempts of non-depressed friends could lead to frustration which in turn could lead to withdrawal from and social rejection of the depressed person (Hale et al., 1997).

With regard to the relationship between illness representations and perceptions of the helpfulness of social support, the results indicate that illness representations are more strongly related to the perceived helpfulness of supportive behaviors in non-depressed persons than in depressed persons. One possible explanation for this result might be that depressed persons evaluate the helpfulness of social support provided by friends primarily in relation to their current mood and need for social support rather than in relation to their generalized representations of depression. In contrast, as never-depressed persons lack own experiences 
with the illness as well as detailed information about situational circumstances, they might base their perceptions of the helpfulness of supportive behaviors on their general ideas about the nature and the causes of depression.

Some limitations of the present study need to be noted. First, data were collected in independent samples of depressed and never-depressed persons. Thus, the study has no dyadic design which would allow an examination of the consequences of discrepant perceptions on social interactions and social functioning within actual relationships. Furthermore, the present study focuses uniformly on friend support and the results cannot be generalized to other support providers (such as spouses or health care professionals) since results from other studies have shown that perceptions of the helpfulness of support behaviors differ depending on which individual of the social network is the provider (Dakof and Taylor, 1990; Warwick et al., 2004). Also, the perceived helpfulness of supportive behaviors was assessed unrelated to the gender of the support recipient and the support provider which might be a relevant issue as previous studies revealed gender differences in coping with depression (Kelly et al., 2007). Finally, the history of depression was assessed via self-reports bearing the possibility that some participants were not willing or not able to provide information about their medical history. Acknowledging these limitations, this study contributes to understanding the processes that underlie the problematic social interactions between depressed patients and healthy persons in the community who may become part of their social network.

In conclusion, the results show that illness representations of depression as well as perceptions of the helpfulness of supportive behaviors diverge between depressed persons and persons with no history of depression. These discrepancies could be a vital source for the commonly reported interpersonal problems and impaired social support processes between depressed persons and their social network. With respect to implications for treatment, addressing interpersonal problems in psychotherapy has been found to be among the most effective treatments of depression (Cuijpers et al., 2008; de Mello et al., 2005). These approaches, such as interpersonal therapy, might benefit from providing clients with information on the likely dissimilarities of illness models and discrepant views on the helpfulness of supportive behaviors between the client and people they meet. On the other end of the stick, our results could help inform the development of appropriate interventions to raise awareness and destigmatization in the community.

\section{Role of funding source}

This study was conducted by Alexander Dienst in the context of his diploma thesis under the supervision of Britta Renner. Klaus Schonauer and Manja Vollmann. Funding was provided by the Committee for Research Funding (AFF) of the University of Konstanz to Alexander Dienst. The AFF had no further role in study design; in collection, analysis and interpretation of the data; in the writing of the report; and in the decision to submit the paper for publication.

\section{Conflict of interest}

All authors declare that they have no conflicts of interest.

\section{Acknowledgements}

The authors would like to thank Günter Schallenmüller and the depression self-help group organization "Balance e.V.", the
Reichenau Psychiatry Center and the public library of Konstanz for providing the opportunity to recruit participants for the present study.

\section{References}

Alexander, J., 2001. Depressed men: an exploratory study of close relationships. J. Psychiatr. Ment. Health Nurs. 8, 67-75.

Angermeyer, M.C., Matschinger, H., 2004. Public attitudes to people with depression: have there been any changes over the last decade? J. Affect. Disord. 83, 177-182.

Barry, M.M., Doherty, A., Hope. A., Sixsmith, J., Kelleher, C.C., 2000. A community needs assessment for rural mental health promotion. Health Educ. Res. 15. 293-304.

Baumann, L.C., 2003. Culture and illness representation. In: Cameron, L.D. Leventhal, H.E. (Eds.), The Self-Regulation of Health and Illness Behaviour. Routledge, New York, pp. 242-253.

Benyamini, Y., Medalion, B., Garfinkel, D., 2007. Patient and spouse perceptions of the patient's heart disease and their associations with received and provided social support and undermining. Psychol. Health 22, 765-785.

Burcusa, S.L., lacono, W.G., 2007. Risk for recurrence in depression. Clin. Psychol. Rev. 27, 959-985.

Cornwall, P.L., Scott, J., Garland, A., Pollinger, B.R., 2005. Beliefs about depression in patients and their partners. Behav. Cognit. Psychother. 33, 131-138.

Coyne, J.C., Gallo, S.M., Klinkman. M.S., Calarco, M.M., 1998. Effects of recent and past major depression and distress on self-concept and coping. J. Abnorm. Psychol. 107, 86-96.

Coyne, J.C., Thompson, R. Palmer, S.C., 2002. Marital quality, coping with conflict, marital complaints, and affection in couples with a depressed wife. J. Fam. Psychol. 16, 26-37.

Cuijpers, P., van Straten, A. Warmerdam, L, 2007. Behavioral activation treatments of depression: a meta-analysis. Clin. Psychol. Rev. 27, 318-326.

Cuijpers, P., van Straten, A., Andersson, G., van Oppen, P., 2008. Psychotherapy for depression in adults: a meta-analysis of comparative outcome studies. J. Consult. Clin. Psychol. 76, 909-922.

Dakof, G.A. Taylor, S.E., 1990. Victims perceptions of social support: what is helpful from whom? J. Pers. Soc Psychol. 58, 80-89.

de Mello, M.F., de Jesus Mari, J., Bacaltchuk, J., Verdeli, H., Neugebauer, R., 2005. A systematic review of research findings on the efficacy of interpersonal therapy for depressive disorders. Eur. Arch. Psychiatry Clin. Neurosci. 255, 75-82.

de Toledo Piza Peluso, E., Blay, S.L, 2009. Public stigma in relation to individuals with depression. J. Affect. Disord. 115, 201-206.

Dienst, A. 2009. Subjektive Krankheitstheorien über Depression: Ein Vergleich von Erkrankten und Nicht-Erkrankten. University of Konstanz, Unpublished Thesis.

Edwards, S., Tinning, L, Brown, J.S.L, Boardman, J., Weinman, J., 2007. Reluctance to seek help and the perception of anxiety and depression in the United Kingdom: a pilot vignette study. J. Nerv. Ment. Dis. 195, 258-261.

Figueiras, M.J., Weinman, J., 2003. Do similar patient and spouse perceptions of myocardial infarction predict recovery? Psychol. Health $18,201-216$.

Fortune, G., Barrowclough, C., Lobban, F., 2004. Illness representations in depression. Br. J. Clin. Psychol. 43, 347-364.

Gladstone, G.L., Parker, G.B., Malhi, G.S.; Wilhelm, K.A., 2007. Feeling unsupported? An investigation of depressed patients' perceptions. J. Affect. Disord. 103, 147-154.

Gräfe, K., Zipfel, S., Herzog, W., Löwe, B., 2004. Screening psychischer Störungen mit dem 'Gesundheitsfragebogen für Patienten (PHQ-D)': Ergebnisse der deutschen Validierungsstudie. Diagnostica 50, 171-181.

Hale [II, W.W., Jansen, J.H., Bouhuys, A.L., Jenner, ] A., van den Hoofdakker, R.H., 1997. Non-verbal behavioral interactions of depressed patients with partners and strangers: the role of behavioral social support and involvement in depression persistence. J. Affect. Disord. 44, 111-122.

Hautzinger, M. 2003. Kognitive Verhaltenstherapie bei Depressionen. Behandlungsanleitungen und Materialien, Beltz, Weinheim.

Heijmans, M., de Ridder, D., Bensing, J. 1999. Dissimilarity in patients' and spouses' representations of chronic illness: exploration of relations to patient adaptation. Psychol. Health 14, 451-466.

Helgeson, V.S., Cohen, S., 1996. Social support and adjustment to cancer: reconciling descriptive, correlational, and intervention research. Health Psychol. 15. 135-148.

Houghton, S., Curran, ]. Saxon, D., 2008. An uncontrolled evaluation of group behavioural activation for depression. Behav. Cognit. Psychother. 36, 235-239.

Keitner, G.J., Ryan, C.E., Miller, I.W., Kohn, R., Bishop, D.S., Epstein, N.B., 1995. Role of the family in recovery and major depression. Am. J. Psychiatry 152, 1002-1008. 
Kelly, M.A. Sereika, S.M., Battista, D.R., Brown, C., 2007. The relationship between beliefs about depression and coping strategies: gender differences. Br. J. Clin. Psychol. 46, 315-332.

Kirk, L., Brody, C., Solomon, A., Haaga, D.A.F., 1999. Lay theories concerning causes and treatment of depression. J. Ration.-Emot. Cognit.-Behav. Ther. $17,237-248$.

Kirk, L., Haaga, D.A.F., Solomon, A., Brody, C., 2000. Perceptions of depression among never-depressed and recovered-depressed people. Cognit. Ther. Res. 24, 585-594.

Kraus, M., Koch, E., 2006. Kultur. In: Stoppe, G., Bramesfeld, A., Schwartz F.-W. (Eds.), Volkskrankheit Depression? Bestandsaufnahme und Perspektiven. Springer, Berlin, pp. 139-162.

Kroenke, K., Spitzer, R.L. Williams, J.B.W., 2001. The PHQ-9: validity of a brief depression severity measure. J. Gen. Intern. Med. 16, 606-613.

Kuyken, W., Brewin, C.R., Power, M..., Furnham, A., 1992. Causal beliefs about depression in depressed patients, clinical psychologists and lay persons. Br. J. Med. Psychol. 65, 257-268.

Lehman, D.R., Ellard, J.H., Wortman, C.B., 1986. Social support for the bereaved: recipients' and providers' perspectives on what is helpful. J. Consult. Clin. Psychol. 54, 438-446.

Leventhal, H., Leventhal, E.A., Contrada, R.J., 1998. Self-regulation, health, and behavior: a perceptual-cognitive approach. Psychol. Health 13, 717-733.

Lynch, T.R., Mendelson, T., Robins, C.J., Krishnan, K.R.R., George, L.K., Johnson, C.S., Blazer, D.G., 1999. Perceived social support among depressed elderly, middle-aged, and young-adult samples: cross-sectional and longitudinal analyses. J. Affect. Disord. 55, 159-170.

Marcus, D.K., Nardone, M.E., 1992. Depression and interpersonal rejection. Clin. Psychol. Rev. 12, 433-449.

Martire, L.M., Keefe, F.J., Schulz, R., Ready, R., Beach, S.R., Rudy, T.E., Starz, T.W., 2006. Older spouses' perceptions of partners' chronic arthritis pain: implications for spousal responses, support provision, and caregiving experiences. Psychol. Aging 21, 222-230.

Moss-Morris, R., Weinman, J., Petrie, K.J. Horne, R., Cameron, L.D., Buick, D. 2002. The revised illness perception questionnaire (IPQ-R). Psychol Health 17, 1 .

Patten, S.B., Schopflocher, D., 2009. Longitudinal epidemiology of major depression as assessed by the Brief Patient Health Questionnaire (PHQ-9). Compr. Psychiatry 50, 26-33.

Petrie, K.J., Weinman, J., 2006. Why illness perceptions matter. Clin. Med. 6. 536-539.

Prins, M.A., Verhaak, P.F., Bensing, J.M., van der Meer, K., 2008. Health beliefs and perceived need for mental health care of anxiety and depression the patients' perspective explored. Clin. Psychol. Rev. 28, 1038-1058.
Quiles Marcos, Y., Weinman, J. Terol Cantero, M.C. Belendez Vazquez, M. 2009. The dissimilarity between patients' and relatives' perception of eating disorders and its relation to patient adjustment. J. Health Psychol. 14. 306-312.

Salewski, C., Bleher, J., 2010. Krankheitskonzepte zu HIV und AIDS: Eine Untersuchung an südafrikanischen und deutschen Patienten. Z. Gesundh. Psychol. 18, 21-30.

Segrin, C. Dillard, J.P. 1992. The interactional theory of depression: a metaanalysis of the research literature. J. Soc. Clin. Psychol. 11, 43-70.

Sheeber, LB., Davis, B., Leve, C., Hops, H. Tildesley, E., 2007. Adolescents' relationships with their mothers and fathers: associations with depressive disorder and subdiagnostic symptomatology. J. Abnorm. Psychol. 116, 144-154.

Slavich, G.M., Thornton, T., Torres, L.D., Monroe, S.M., Gotlib, L.H., 2009. Targeted rejection predicts hastened onset of major depression. J. Soc. Clin. Psychol $28,223-243$.

Spitzer, R.L. Kroenke, K., Williams, J.B.W., 1999. Validation and utility of a self-report version of PRIME-MD. J. Am. Med. Assoc. 282, 1737.

Stice, E., Ragan, J., Randall, P., 2004. Prospective relations between social support and depression: differential direction of effects for parent and peer support? ]. Abnorm. Psychol. 113. 155-159.

Strine, T.W., Kroenke, K., Dhingra, S., Balluz, LS., Gonzalez, O., Berry, JT. Mokdad, A.H , 2009. The associations between depression, health-related quality of life, social support, life satisfaction, and disability in communitydwelling US adults. J. Nerv. Ment. Dis. 197, 61-64.

Wade, T.D., Kendler, K.S., 2000. The relationship between social support and major depression: cross-sectional, longitudinal, and genetic perspectives. ]. Nerv. Ment. Dis. 188, 251-258.

Warwick, R., Joseph, S., Cordle, C., Ashworth, P., 2004. Social support for women with chronic pelvic pain: what is helpful from whom? Psychol. Health 19, 117-134.

Weinman, J. Heijmans, M., Figueiras, M.J., 2003. Carer perceptions of chronic illness. In: Cameron, L.D., Leventhal, H. (Eds.), The Self-Regulation of Health and Illness Behaviour. Routledge, New York, pp. 207-219.

Winkeler, M. Klauer, T. 2003. Inventar zur sozialen Unterstützung in Dyaden (ISU-DYA): Konstruktionshintergrund und erste Ergebnisse zu Reliabilität und Validität. Diagnostica 49, 14-23.

Wortman, C.B., Lehman, D.R., 1985. Reactions to victims of life crisis: support attempts that fail. In: Sarason, I.G., Sarason, B.R. (Eds.), Social Support: Theory Research, and Applications. Martinus Nijhoff, Dordrecht, pp. 463-490

Zuroff, D.C., Blatt, S.J., 2002. Vicissitudes of life after the short-term treatment of depression: roles of stress, social support, and personality. J. Soc. Clin. Psychol. 21, 473-496. 